\title{
First language attrition and syntactic subjects: A study of Greek and Italian near-native speakers of English
}

\section{lanthi Tsimpli ${ }^{1}$, Antonella Sorace ${ }^{2}$, Caroline Heycock ${ }^{2}$, and Francesca Filiaci $^{2}$}

\author{
${ }^{1}$ Aristotle University of Thessaloniki \\ ${ }^{2}$ University of Edinburgh
}

\section{Acknowledgment}

This research was supported by ESRC grant R000239158.

\section{Abstract}

In this paper we present some results from an experimental study that we have been conducting into the effects of syntactic attrition on the L1 of Greek and Italian speakers who have achieved near-native proficiency in their L2 (English) but still use their L1 on a regular basis. In particular, we test the hypothesis, developed on the basis of assumptions regarding syntactic modularity, that the changes in L1 syntax will be restricted to the interface with the conceptual/intentional cognitive systems. The area of investigation is the domain of grammatical subjects in Greek and Italian. More specifically, we tested the participants on the production and interpretation of null and overt subjects, and of preverbal and postverbal subjects. We also elicited grammaticality judgments on subject extraction and subject position in various syntactic contexts. In this paper we report on the results of one of the production tasks (of preverbal and postverbal subjects) and two interpretation tasks. Attrition effects are found in the production of preverbal subjects in the Greek group whereas Italian speakers show attrition effects in the interpretation of overt pronominal subjects. We argue that these results are in the right direction, that is, that semantic features are vulnerable in language attrition whereas syntactic options remain intact.

\section{Introduction}

The issue of near-nativeness in adult second language (L2) acquisition has been a focus of much recent research, and it has been demonstrated that certain syntactic constraints which are categorical for "true" native speakers are optional for near-natives (Beck, 1998; Robertson \& Sorace, 1999; Sorace 2000). However, while the residual optionality found in L2 end-states can in most cases be attributed to the persistent influence of the learners' L1 on the L2, there has been much less research on possible effects in the opposite direction: attrition. Further, the majority of work on attrition has been concerned with migrant communities, usually characterized by diminished use of the 
L1, separation from the L1-speaking community, low degree of acculturation, and a low level of L2 attainment at least in the first generation (Håkansson, 1995; Lambert \& Freed, 1982; Montrul, 2002; Silva-Corvalan, 1991; Weltens, de Bot, \& van Els, 1986). In this paper we present some results from an experimental study that we have been conducting into syntactic attrition in a very different group of subjects: those adults who continue to use their L1 on a regular basis, but who have in addition achieved near-native proficiency in the L2. This is one of the very few full-scale experimental studies of syntactic attrition in a group of advanced (near-native) learners of English (see also Gürel 2002)1.

\section{On subjects in syntactic theory}

In the generative framework, first language acquisition is a process of parameter setting (Chomsky, 1986, 1995). The setting of parameters to different values is what gives rise to syntactically distinct languages. The locus of crosslinguistic variation (parameterization) is supposed to be in the Lexicon, and in particular, in the morphological features of functional categories (Chomsky, 1995). We can then understand parameter-setting to refer to the appropriate selection of morphological features (and their values) on the functional categories of a particular language. In this respect, the steady-state of the grammar in the native speaker's mind includes parameters set to the target value.

If we were to take syntactic attrition to be a set of changes in L1 syntactic competence this would be, formally, translated as loss or resetting of L1 parametric values under L2 influence. However, given that within the same individual, the autonomous existence of two or more native or non-native grammars is possible in multilinguals, this view of the nature of syntactic attrition seems implausible (Meisel, 1994; White, 2000). An alternative view is that the differences between two languages go beyond different parameter settings: the grammatical options provided by these settings may in addition be recruited to achieve various semantic/pragmatic effects. It is the exact nature of this exploitation of the grammatical options, it may be suggested, which can be affected as a consequence of attrition.

Within the Minimalist version of the Principles and Parameters framework (Chomsky, 1995) this distinction corresponds to a distinction between two different classes of features. Uninterpretable features, such as Case and Agreement on verbs and all other items not intrinsically specified for person, number and gender, drive the syntactic derivation. Some aspects of these uninterpretable features may be parameterized to yield the different syntactic options available in different languages. Interpretable features on the other hand have interpretative effects - they can be "read" by the conceptual/intentional systems of cognition.

The distinct role of interpretable and uninterpretable features can be understood in relation to the distinction between the syntactic derivation and the LF-interface. Specifically, parameters which are responsible for crosslinguistic differences are associated with the value of uninterpretable features only (cf. Borer, 1984; Chomsky,

1 To the best of our knowledge, the only other study that investigates adult L1 attrition in end-state speakers is Gürel (2002). The subjects tested in Gürel's study were L2 speakers of English and had retained use of Turkish L1. 
1995; Ouhalla, 1991). Interpretable features are not parameterized in the same way, but they can exploit parametric values.

As a prototypical example of a parameter, consider the availability of null subjects in Italian and English: Italian allows null subjects in finite clauses whereas English lacks this option, as shown by the examples in (1): ${ }^{2}$

1. a. E' partito

is-3s gone-M

'He left.'

b. *(He/she) left.

Under the assumptions we have outlined, this means that some functional head(s) in Italian and English (Inflection or Agr-S) is set differently for whatever feature(s) gives rise to this difference, which we can refer to as the Null Subject Parameter (NSP) (Rizzi, 1982, 1986). More specifically, in languages like Greek and Italian, agreement features are morphologically realized in a rich paradigm which interacts with Tense distinctions, whereas English has no corresponding richness in the inflectional domain.

Another syntactic option that arises from the NSP concerns the availability of postverbal subjects. In particular, postverbal subjects are possible in null subject languages like Italian and Greek but disallowed in English (Rizzi, 1982, 1986), as illustrated in (2):

\section{2. a. E' partito Gianni.}

is gone-M John

'John left.'

b. * Left John.

The examples in (1) and (2) illustrate two relevant syntactic differences between null subject languages, like Italian, and non-null subject languages, like English. There are, however, additional effects that rely on the null-subject setting of the NSP, which can be found in the interpretative component of natural language grammar, that is, the syntax-discourse interface usually associated with the LF level of syntactic representation (Platzack, 1999).

First, with respect to subject pronouns, the null option is considered to be the default in null subject languages whereas the overt pronoun is the "marked" option (Cardinaletti \& Starke, 2001; Montalbetti, 1984). To simplify a very complex picture, an overt subject pronoun is used when topicalization or focusing of the subject is required (see the Greek examples in ( $3 a$ and $b)$ ).

3. a. Context: Both John and Mary have bought this new book.

*(Aftos) tis to protine.

he her it recommended

'He recommended it to her' [ $\mathrm{He}$ is contrastive topic]

2 In this paper we discuss both Greek and Italian. Where the phenomena are the same in both languages, we illustrate with examples from one language only, for reasons of space. 
b. Context: I don't know if John and Mary will come to the party.

*(Afti), tha erthi.

she will come

'SHE will come.' [She is focused]

Furthermore, reference assignment to subject pronouns differs depending on the null or overt nature of the pronoun. The choices are illustrated in the Greek examples in (4) below:

4. a. O Janis prosvale ton Petro $_{k}$ otan $_{\text {pro }} /$ Ifftos $_{k}$ ton plisiase.

the Janis insulted the Petro when pro/he him approached

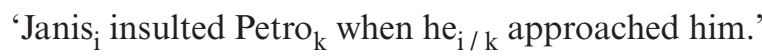

b. O Janis ${ }_{i}$ idhe ton Petro ${ }_{k}$ otan AFTOS $_{k}$ ton plisiase.

'Janis ${ }_{\mathrm{i}}$ saw Petro $_{\mathrm{k}}$ when $\mathrm{HE}_{\mathrm{k}}$ approached him.'

In (4a), the use of the pro (null) subject leads to a nonshifted interpretation for the embedded subject (it is interpreted as being coreferential with the matrix subject). On the other hand, if the overt subject pronoun (aftos) is used, the antecedent cannot be the matrix subject (and so in this particular context the matrix object is picked). In (4b), the antecedent for the overt pronoun is, again, the matrix object; in this case the pronoun is additionally licensed by focus ${ }^{3}$.

Turning to the second syntactic consequence of the null-subject option of the NSP, namely the possibility of subjects appearing in postverbal position, here too this syntactic option can be exploited for particular semantic effects. That is, there are constraints of a semantic or thematic nature which regulate the distribution of preverbal and postverbal subjects in null subject languages. Specifically, the choice of postverbal over preverbal subjects in Greek and Italian one-place predicates is regulated by (i) the definiteness of the subject (cf. Belletti, 1988), as shown in (5), and (ii) the thematic properties of the verb (Pinto, 1997), as shown in (6) and (7). Here we give Greek examples.

5. a. Eftasan kapji fitites.

arrived-3P some students

b. I fitites eftasan.

the students arrived-3P

6. a. Edho dulevio Yanis.

here works the-NOM Yanis

b. \#Edho o Yanis dulevi.

here the-NOM Yanis works

3 As pointed out by an anonymous reviewer, the overt subject pronoun in (4b) and the one in (4a) both have a contrastive interpretation, in that the antecedent of the pronoun is marked (i.e., the matrix object). However, in (4a) the overt pronoun need not carry heavy stress and, we claim, no focus feature is assigned. This difference in the stress pattern has, however, additional effects on interpretation: the stressed pronoun has a demonstrative function whereas in (4a) it is a personal pronoun without further deictic properties. 


\section{7. a. Sto telos tis teniaso Yanis jelase.}

at the end of the movie the-NOM Yanis laughed

b. \# Sto telos tis tenias jelase o Yanis.

at the end of the movie laughed the-NOM Yanis

As illustrated in (5), the one-place predicate ftano (arrive) favors the preverbal position for definite subjects and the postverbal position for indefinites. With respect to a class of predicates exemplified in (6) by the verb work, Pinto (1997) argues that their thematic structure includes an additional locative argument which can be either overt as in (6) or not. The locative argument can occupy the subject position and thus satisfy the requirement for a subject in the preverbal position (known as the EPP feature of Tense (Chomsky, 1995)). As a result, the NP argument $o$ Yanis (John) appears in postverbal position in (6a). The marginal status of (6b) indicates that the locative is indeed an argument rather than an adjunct since only one argument is required, and therefore allowed, to satisfy the EPP feature. On the other hand, laugh-type verbs are true one-place predicates and thus require their NP argument to appear in preverbal position as shown by the grammaticality of (7a) and the marginal status of (7b $)^{4}$.

Notice that the thematic difference between work - and laugh-type predicates is not language-specific. Thus the corresponding English predicates should also involve this difference (the presence vs. absence of a locative argument). However, the thematic difference can have syntactic effects only in languages where its expression via the variability in subject position is already a grammatical option (because of the null-subject option of the NSP).

Turning now to the Greek examples in (5), we may note that definiteness effects are also found in the syntax of English, as shown by (8) below (Diesing, 1991):

8. a. There is a $/ *$ the student waiting for you.

A student/The student is waiting for you.

Although definiteness is thus grammaticalized both in null subject languages like Greek or Italian and non-null subject languages like English, the link between the availability of postverbal subjects and their [-definite] specification presupposes the positive setting of the NSP. In other words, definiteness distinctions can only impose interpretative differences on preverbal and postverbal subjects in languages where variation in subject position is available for independent (parametric) reasons.

A third interpretative distinction that arises in a null-subject language concerns the effect of position on the interpretation of indefinite subjects: preverbal indefinite subjects are interpreted as "old" information (topic) whereas postverbal indefinite subjects are ambiguous between the "old" and the "new" interpretation, as shown by the Greek examples in (9):

\section{Context: I gitonisa mu ston trito orofo apektise dhidhima.}

'My neighbor on the third floor had twins.'

4 The status of (6b) and (7b) is marginal rather than ungrammatical due to the possibility of alternative structures with the initial adverbials in some left-peripheral A-bar position (as suggested by distinct intonation for such examples). 

a. Xtes vradhi ena moro ekleje.
last night one baby was-crying ( = one of the twins)
b. Xtes vradhi ekleje ena moro.
last night was-crying one baby ( = one of the twins $O R$ some other baby)

This possibility is again associated with the common assumption in the literature of null subject languages that the preverbal position hosts subject topics (e.g., Cardinaletti, 1997, for Italian; Philippaki-Warburton, 1987, \& Tsimpli, 1990 for Greek a.o.). This interpretative distinction is again possible due to the null-subject option of the NSP which renders the postverbal position a grammatical possibility for the subject. It should be noted, however, that Greek differs from Italian with regard to postverbal subjects: Greek is a VS(O) language, the postverbal option being unmarked with respect to its interpretation, whereas Italian reserves the postverbal subject position for new information focus (Belletti, 2001; Roussou \& Tsimpli, to appear). In other words, whereas Italian associates the postverbal position with an interpretative function, Greek uses the same grammatical option for no such effect.

To summarize, we have introduced two syntactic options arising from the nullsubject option of the NSP: the availability of null subjects in finite clauses and of postverbal subjects. In addition, we have argued that these two options are then "exploited" according to certain interpretative features. In particular, overt pronominal subjects are associated with the features of topic, topic-shift and focus (see (3) above). The topic feature is also responsible for the distribution of definite and indefinite subjects on the assumption that a definite subject can readily be interpreted as a topic, whereas an indefinite one is more likely to be new information (see (5) above). The topic feature is also relevant to the interpretation of indefinite subjects in preverbal as opposed to postverbal position (see (9) above). According to this difference, a preverbal indefinite, being interpreted as a topic, has a specific reading whereas a postverbal one is ambiguous between the specific and the nonspecific indefinite reading. As such it may refer to entities not mentioned in the preceding discourse. Finally, the distribution of preverbal and postverbal subjects in null subject languages is also linked to thematic differences between predicates that appear to have one argument only.

We next turn to our general hypothesis concerning the nature of syntactic attrition, and the specific predictions that this theory makes with regard to attrition effects in the domain of subjects that we have just discussed.

\section{Interpretability of features and syntactic attrition}

In the previous section we have distinguished between the syntactic options available in a language and the various semantic/pragmatic/discourse effects that may follow from the employment of one or another option.

Specifically, the NSP is an example of a parameter which, on the one hand, determines syntactic differences between languages, and, on the other, "feeds" interpretable features like topic, focus, and definiteness, which regulate the distribution and interpretation of the formal options. In other words, the nature of Agr (verbal agreement) in Italian and Greek versus English is responsible for the setting of the NSP in the 
former languages and hence for the availability of null and of postverbal subjects. But the way in which Italian and Greek distribute and interpret null and overt subjects as well as preverbal and postverbal subjects stems from the implementation of interpretable features assigned to the syntactic options already available. This implementation takes place at the LF-interface where semantic and discourse-related features which are represented in the syntactic structure become available for further processing in central cognition.

Our hypothesis is that syntactic attrition primarily affects morphosyntactic features that are interpretable at the LF interface but leaves unaffected uninterpretable features, which regulate parametric syntax (Sorace, 2000). This hypothesis relies on the following assumptions: First, after the Critical Period is over, the native speaker of a language is in a steady/mature state with regard to his linguistic competence; this cognitive state does not allow for optional syntactic processes (Chomsky, 1995; contra e.g., Grimshaw $\&$ Samek-Lodovici, 1998). Second, the syntactic computation driven by the set of uninterpretable features which determine parameters, is modular and therefore does not allow for top-down effects (e.g., the influence of interpretative properties) on syntactic derivations. Third, the LF-interface and the representation it yields is not modular, unlike the process of syntactic derivation (cf. Platzack, 1999). Thus, interpretable features at the LF-interface are vulnerable to attrition.

Specifically, we expect $\mathrm{L} 1$ attrition to involve interpretable features that are linked to a parametric choice that differs between the L1 and the L2. In this way, an interpretable feature that is specified in L1 in a particular syntactic structure will become unspecified due to the absence of a similar interpretable feature in L2 in the same syntactic context $^{5}$. This underspecification gives rise to optionality (see Sorace, 1993, 2000). Attrited grammars are then expected to show more "ambiguity" in the interpretation of lexical items (null or overt) since conflicting options associated with L1 and L2 will be accessible at the interface. However, uninterpretable feature values that distinguish between the parametric choices of L1 and L2 will not be affected through attrition and therefore no optional "syntax" is expected to be found.

\section{1}

\section{Predictions for attrition effects in the domain of "subjects"}

Our aim in this study was to investigate syntactic attrition in the domain of grammatical subjects in Greek and Italian near-native speakers of English. More specifically, the areas of investigation presented in this paper are: elicited production data of preverbal and postverbal subjects (e.g., (2)), elicited interpretation of overt indefinite subjects in preverbal and postverbal position (e.g., (9)) and of overt and null subject pronouns in contexts of backward or forward anaphora (e.g., (4)).

The hypothesis outlined in the previous section yields some qualitative predictions regarding the status of subjects in the attrited grammars of Greek and Italian. With

5 The directionality of the attrition effects with respect to interpretative properties is predicted to be from the more to the least "economical" grammar. In the case of subjects, the English grammar does not offer any interpretive option associated with different syntactic choices whereas the Italian and the Greek grammar do. This is also consistent with early descriptive remarks that attrition leads to a "reduction" in the range of possibilities offered by a language. 
respect to null and overt subjects, we predict that both of these syntactic options will remain unaffected in Greek and Italian (given that this is a parametric choice regulated by an uninterpretable feature). On the other hand, attrition effects are expected in the distribution and interpretation of overt pronominal subjects in L1 Greek and Italian (given that this is regulated by the interpretable [topic-shift] and [focus] features). The relevant interpretable features on overt pronominal subjects become unspecified and therefore these subjects will not necessarily be interpreted as shifted topics or as foci in attrited Greek or Italian. This prediction extends to the interpretation of preverbal (indefinite) subjects: They are predicted to be optionally assigned a topic reading under the influence of preverbal subjects in the English L2. On the other hand, given that postverbal subjects remain a syntactic option and this option is not shared by the second language, their interpretation is predicted not to be affected by attrition.

The production of preverbal and postverbal subjects will remain unaffected (again because the choice stems from the parametric option of the NSP), but the relative frequency of preverbal subjects will increase under the influence of L2 English. Note that this prediction is still based on the qualitative change in the attrited grammar in the sense that the preverbal subject position will no longer be linked to the topic reading. The effect of this lack of specification, however, will be evidenced quantitatively in an increased production of preverbal subjects which may or may not function as topics, as is the case in the English L2. The implication is that thematic properties associated with the preference for preverbal or postverbal subjects in monolingual Greek or Italian speakers will be overriden by L2 options, leading to attrition.

\section{Subjects and Methodology}

\section{1 \\ Subjects and general design}

Four groups of subjects participated in the study: one group of Italian near-native speakers of English $(n=20)$, one group of Greek near-native speakers of English $(n=$ $19)$, one group of Italian controls $(n=20)$ and one group of Greek controls $(n=20)$. Subjects in the experimental groups (Greek and Italian near-native speakers of English) had a minimum of six years of residence in Britain, used L1 and L2 in everyday contexts and their level of English (L2) is near-native according to White \& Genesee's (1996) criteria. ${ }^{6}$ Subjects in the control groups live in Italy and Greece respectively and have minimum or no knowledge of English.

We selected subjects who reported themselves as using their $\mathrm{L} 1$ on a regular basis because we were primarily interested in the effects of attrition on competence. Lack of use of the L1 would lead to lexical attrition (Seliger, 1991) and therefore to word-retrieval

6 White and Genesee's criteria include advanced performance in morphology, syntax, vocabulary, fluency, and pronunciation. Assessment of these levels is based on spoken production data in the L 2 which is then evaluated by two independent judges who are native speakers of the language in question. The evaluation is diagrammatically represented on a scale for each of the components assessed. It should be noted, however, that in our study we had to modify the criteria by slightly reducing the cut-off point for the selection of near-native subjects. This is due to the fact that Britain is not a bilingual country (unlike Canada, where Genesee \& White were working), and as a result, near-native competence (particularly at the level of pronunciation) in the L2 is much harder to find. 
difficulties which would inevitably affect the speakers' production. More generally, it might lead to performance difficulties that could obscure any underlying competence effects. On the other hand, we selected subjects whose level of English was near-native, and who had at least six years of residence in Britain because of our expectation that syntactic attrition would occur as the result of long-term contact with the second language (rather than extensive instruction) and that it would be most advanced in highly proficient speakers of the L2. These expectations were not hypotheses which the study was designed to test experimentally. We have however investigated the possibility of establishing a correlation between degree of attrition and length of stay, reported extent of L2 versus L1 use, and L2 proficiency: this will be discussed in Section 5.4 below.

The study consisted of four tasks testing production and comprehension of null and overt NP and pronominal subjects, and a grammaticality judgment task. This paper is restricted to the presentation of relevant data from one production task ("Headlines"), and one comprehension task ("Picture Verification"). Sample materials used in these tasks are in the Appendix. For reasons outlined in Section 5, we present some data from the Greek speakers only, and some from the Italian speakers only. ${ }^{7}$

\section{2}

\section{The Headlines Task}

In this production task the subject was asked to produce a sentence consisting of a given verb, an NP and an adverbial expression, presented to him/her as scattered phrases on the computer screen. The phrases were presented together with a picture depicting the story meant to be described by the phrases. The subject was asked to produce a sentence starting with the phrase Did you hear that .... In half of the cases the subject was indefinite (e.g., ... a building collapsed because of an explosion); in the other half definite ( ... the Wimbledon tournament started in bad weather). There were 30 experimental items in total (15 sentences with definite subjects and 15 with indefinite subjects). The order of presentation was randomized at every run of the experiment. See Appendix, Item $\mathrm{A}$, for an example.

The aim of the task was to test the use of preverbal and postverbal subjects in this all-focus context. The postverbal position was predicted to be preferred by the control group to a greater extent than by the experimental group, given our prediction that attrition would lead to an increased frequency in the use of the preverbal option.

\section{3}

\section{The Picture Verification Task}

In this task there were two types of test items. In the first, the subject was presented with a sentence and a set of three pictures (presented in randomized order for each subject) and was asked to indicate which of the three pictures matched correctly the meaning of the sentence. (See Appendix, Item B, for an example.) The sentence consisted of two clauses, one main and one subordinate. The subject of the main clause was always an $\mathrm{NP}$; the subject of the subordinate clause could be either an overt pronoun or a null

7 The full report is available from the project web site:

$<$ http://www.ling.ed.ac.uk/research/gsyntax/attrition-project>. 
subject. The number of participants in the pictures was at least two and at most three, allowing for the possibility of a third referent in the discourse being the antecedent of the embedded subject pronoun. The main clause always had an animate complement. The subordinate clause could either precede or follow the main clause (forward or backward anaphora):

10 a. Quando le $i_{k / l} / \mathrm{pro}_{i}$ attraversa la strada, l'anziana signora saluta la ragazza $_{k}$. while she crosses the street the old woman greets the girl

'While she/pro crosses the street, the old woman greets the girl.'

b. L'anziana signora ${ }_{i}$ saluta la ragazza ${ }_{k}$ quando le $i_{k / l} / \mathrm{pro}_{i}$ attraversa la strada the old woman greets the girl when she crosses the street

'The old woman greets the girl when she/pro crosses the street.'

There were 20 experimental items of this type in total. In half of them the experimental sentence contained an instance of backward anaphora and in the other half it contained an instance of forward anaphora, for each type of anaphora half of the sentences (i.e., 5) contained a null subject and the other half contained an overt subject. The aim of the task was to identify the preferred interpretation for the referent of the subject of the subordinate clause (see Appendix for the instructions used for this task).

The other test items had the same presentation as the first but in this case there were two sentences in each item. The first sentence provides a possible set of referents and an event, and the second includes a singular indefinite subject in either preverbal or postverbal position. The aim of the task was to identify a preference for the "old" or "new" referent interpretation, or a lack of preference (ambiguity). (See Appendix, Item $\mathrm{C}$, for an example and the instructions given.) There were 10 of these items in total, in half of them the subject of the second sentence was in preverbal position, in the other half it was in postverbal position.

The task also contained 10 filler items. The structure of these was the same as that of the experimental items, that is to say, one sentence was presented on top of the screen together with three different pictures. The meaning of the filler sentences was never ambiguous in that only one of the three pictures matched it correctly. The three types of items (anaphora items, preverbal and postverbal items and fillers) were presented in a random order.

\section{Results}

In what follows, results from production and interpretation tasks are presented only from one of the two languages tested. Specifically, the Greek production data come from the Headlines task and the second type of test items in the interpretation task (Picture Verification Task). The Italian data come from the four conditions used in the first type of the PVT. Apart from lack of space, this "selective" presentation of data is due to a number of reasons. First, more differences were obtained between the Italian and the Greek groups than predicted. For example, production of preverbal and postverbal subjects by Italian controls seems to be determined by the (in) definiteness 
of the subject whereas Greek controls produce more postverbal subjects regardless of definiteness (see fn. 7 for access to the results through our webpage). This difference can be attributed to the unmarked nature of postverbal subjects in Greek but not in Italian (see Section 2 above). Nevertheless, the issues raised by these differences have implications for the predicted attrition effects for each language group in relation to features such as definiteness, which have not been explicitly included in our original hypotheses. Second, in some cases significant effects were obtained only for one of the two languages. Third, two of the production tasks (the Cartoons task and the Storytelling task) did not produce any significant results for either group.

\section{1}

\section{Headlines Task (Greek)}

As Figure 1 shows, there is a significant difference between the two groups of Greek speakers in their production of preverbal definite subjects in the Headlines Task, $F(1,37)=9.848, p=.003$.

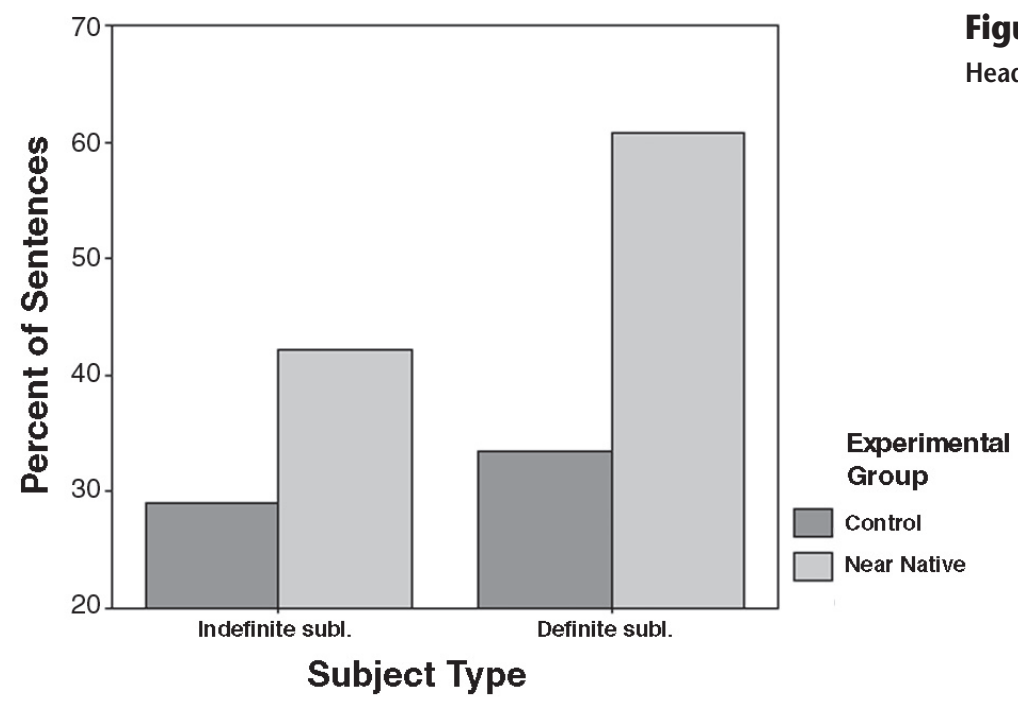

There is also an interaction of definiteness and group (Definiteness $\times$ Group: $F(1,37)=4.018, p<.05)$.

\section{2}

\section{Picture Verification Task: interpretation of indefinite subjects [Greek]}

Figures 2 and 3 show the results from the second type of items in this task for the Greek speakers. The task here concerned the interpretation of indefinites in pre- and postverbal position as "old" or "new." Subjects were permitted to pick more than one picture, as reflected in the figures for "both"; completely irrelevant answers were classified as "non valid." Figure 2 gives the interpretations that were associated with preverbal indefinites, and Figure 3 those that were assigned to postverbal indefinites. 


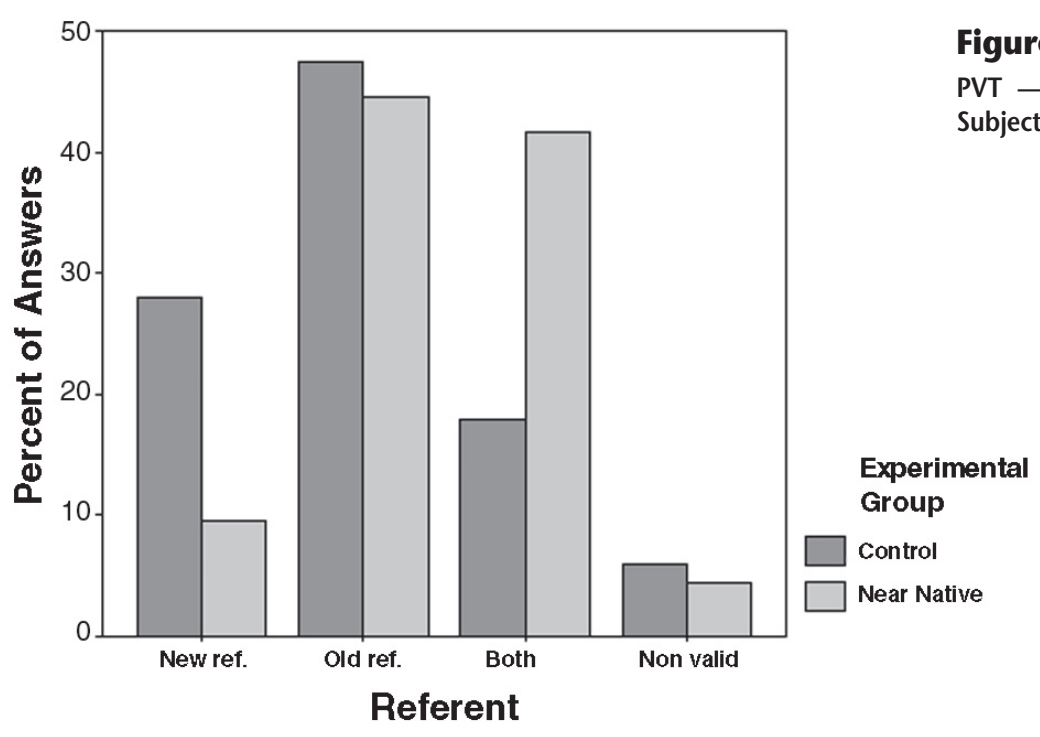

Figure 2 shows significant differences between the control and experimental groups in how often they interpreted a preverbal subject as "new", $F(1,37)=12.14 p<.001$, and how often they picked both the old and the new interpretation, $F(1,37)=8.612$ $p<.006$. There is an effect of Reference, $F(3,37)=21.62, p<.0001$, an interaction between Reference and Group, $F(3,37)=5.512, p<.001$, and an intraction between subject position and Reference, $F(3,111)=9.47, p<.0001$. These results indirectly support our prediction, showing that the interpretation of preverbal subjects is more ambiguous in the experimental group than in the controls.

In Figure 3, which shows the interpretations given to postverbal indefinite subjects,

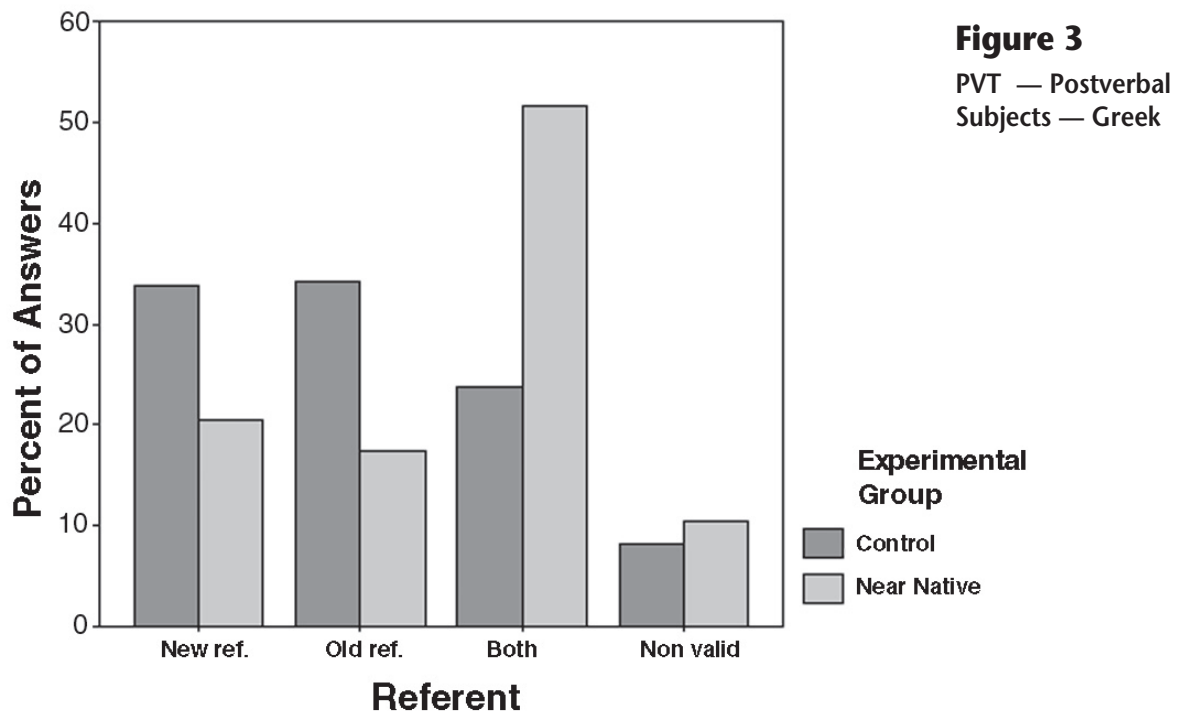


the difference between the groups in the frequency of an "old" interpretation is significant, $F(1,37)=6.962, p<.02$.

The two groups are also significantly different with regard to the choice of both the "old" and the "new" interpretation, $F(1,37)=7.243, p<.01$. Although our prediction was that the interpretation of postverbal subjects should not be affected by attrition, the results show that there is increased indeterminacy in the interpretation of postverbal subjects in the responses from the experimental group. This is possibly a side-effect of attrition found in the interpretation of preverbal subjects.

\section{3}

\section{Picture verification task: interpretation of null and overt pronouns (Italian)}

Figures $4-7$ show how the two Italian groups interpreted null and overt subject pronouns in situations of possible forward and backward anaphora. Figure 4 shows the interpretations given for a null pronoun in a situation of possible forward anaphora. A sentence of this type is provided in (11):

11. Quando pro attraversa la strada, l'anziana signora saluta la ragazza. when crosses the street the old woman greets the girl

'When (she) is crossing the street, the old woman greets the girl.'

The three referents that could be picked for the null pronominal in the initial adverbial clause were the subject of the main clause (the old woman), the object (the girl) or some other person not mentioned in the sentence.

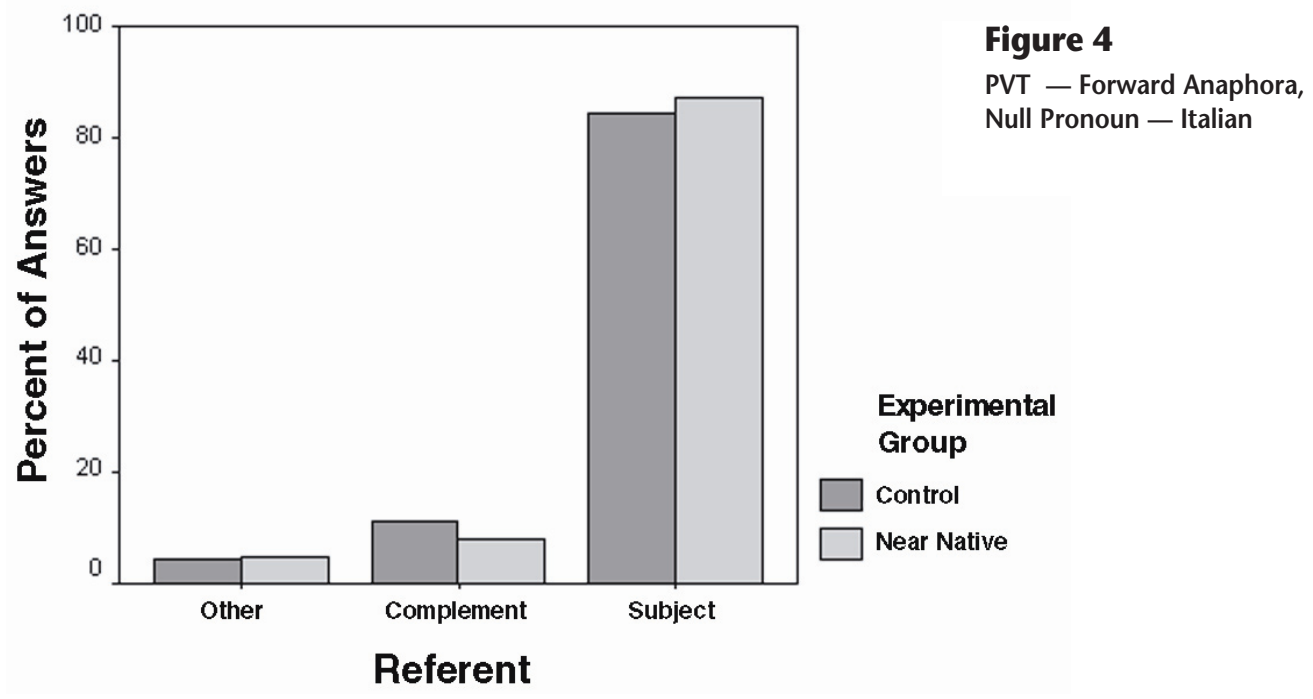

There was no significant difference here between the behavior of the control and experimental groups with respect to the referent of the null pronoun in this condition (Main effect for Referent, $F(2,38)=322.74, p<.0001$, but no significant main effect for Group or Referent $\times$ Group interaction). 
Figure 5 shows the results for the same type of sentence but with an overt pronoun (lei 'she') rather than the null pronominal, as in (12):

12. Quando lei attraversa la strada, l'anziana signora saluta la ragazza. when she crosses the street the old woman greets the girl

'When she is crossing the street, the old woman greets the girl.'

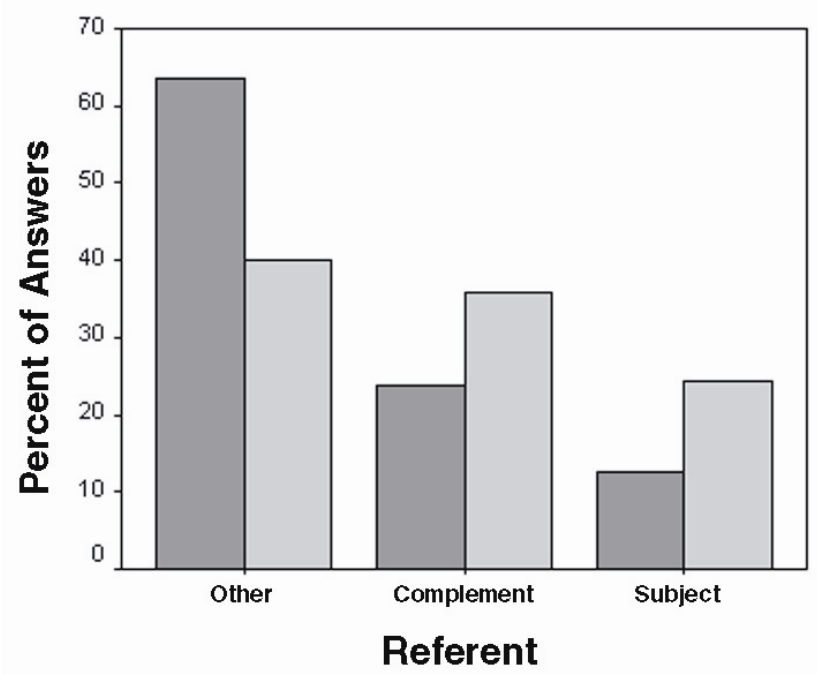

Figure 5

PVT - Forward Anaphora, Overt Pronoun — Italian

In this condition there is a significant difference between the behavior of the control and experimental groups (Referent $\times$ Group: $F(2,38)=3.877 ; p<.025$ ). This is primarily due to the responses to the "Other" referent (controls: 63.6\%; experimental group: $39.9 \%, p<.022$ ).

Figure 6 shows the referents attributed to a null pronominal subject in the condition of backward anaphora, as in (13).

13. L'anziana signora saluta la ragazza quando pro attraversa la strada the old woman greets the girl when crosses the street

'The old woman greets the girl when she is crossing the street.'

There is a significant interaction between Referent and Group here, $F(2,38)=$ 8.433; $p<.0001$, due to the difference between the controls and the experimental group for the "Subject" choice $(50.75 \%$ vs. $69.8 \%$, respectively, $F(2,38)=8.49, p<.006)$ and for "Complement" (44.05\% vs. 24.85\%, respectively; $F(2,38)=10.48, p<.003)$.

Finally, Figure 7 gives the figures for the referents associated with an overt pronominal in the same condition of backward anaphora, as in (14):

14. L'anziana signora saluta la ragazza quando lei attraversa la strada. the old woman greets the girl when she crosses the street

'The old woman greets the girl when she is crossing the street.' 

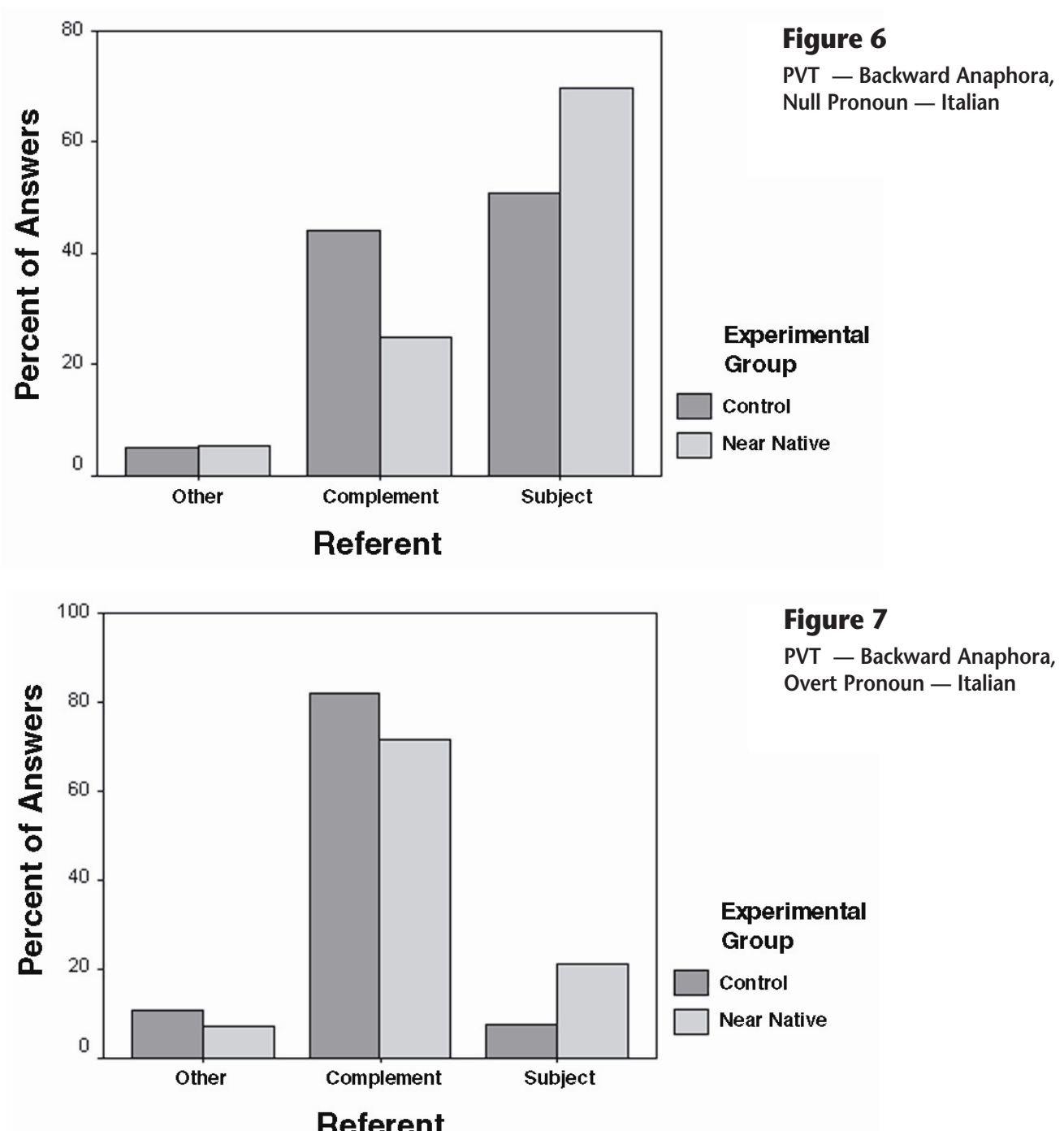

Figure 7

PVT - Backward Anaphora, Overt Pronoun — Italian

Here again there is a significant interaction between Referent and Group, $F(2,38)=3.405 ; p<.049$. This effect results from the choice of matrix subject as a potential referent for the overt pronoun ( $7.6 \%$ for the controls vs. $21.15 \%$ for the experimental group). The difference between the groups is significant, $F(2,38)=6.682, p<.014$.

\section{4}

\section{Variation between experimental subjects}

As stated in Section 4.1, this study was not designed to test for the correlation of attrition with any other factor. As there were some differences between our subjects with respect to the length of their residency in Britain, the balance of their use of L1 and L2, and their proficiency in the L2 (within the limits we had defined) we did test for correlations 
between these factors and their degree of attrition as measured by deviance from the judgments of the control group. No such correlations could be established.

\section{Discussion}

First, let us consider the production task reported here (the "Headlines" task), which tested the production of pre- and postverbal subjects ${ }^{8}$. As shown in Figure 1, the Greek experimental group prefers the preverbal subject position for both definite and indefinite subjects to a greater extent than the controls. The difference between the experimental and the control groups in the production of preverbal definite subjects is significant in this task. This result supports the original hypothesis, that is, that production of preverbal subjects will increase as a result of attrition.

A definiteness effect is also found in the within-groups analysis in the data from the experimental group. Definites are preferred in preverbal position and indefinites in postverbal position. This is probably associated with the default interpretation of a definite subject as a topic, assumed to be a universal (semantic/pragmatic) condition, hence not affected by syntactic attrition. Given that nonattrited Greek does not use definiteness to determine the distribution of preverbal and postverbal subjects, as shown by the controls' data, the performance of the experimental group indicates that, in language attrition, the increase in the use of preverbal subjects under L2 influence may give rise to the introduction of other semantic (interpretable) features, like definiteness in order to regulate the syntactic distribution of subjects in pre- or postverbal position. The controls, on the other hand, show a syntactic preference for postverbal subjects which overrides any effect of definiteness / topichood that governs the behavior of the experimental group.

With respect to the data from the test items in the comprehension (Picture Verification) task that tested the interpretation of indefinite subjects in pre- and postverbal position, the Greek experimental group showed an increased indeterminacy (choosing "both" old and new reference) in their interpretation of both preverbal and postverbal indefinite subjects compared to the controls (Figures 2 and 3). With respect to preverbal indefinite subjects (as in (9a)) both groups show a similar preference for the "old" referent interpretation ( $45 \%$ vs. $47 \%$ ). Postverbal subjects as in ( $9 \mathrm{~b}$ ) are sometimes interpreted as "new" and sometimes as "old" by the controls, whereas the experimental group shows ambiguity in half of the cases. We assume that there is a difference between choosing either "old" or "new" on one hand, and choosing "both" options on the other. Presumably for both groups the postverbal position is not associated with a particular interpretation, as pointed out in Section 2. Thus, we assume that the control group decides on the "new" or "old" interpretation on the basis of contextual or lexical preferences, given that the syntax does not impose interpretative restrictions on postverbal subjects. If this is the case, then the fact that the experimental group shows increased ambiguity possibly indicates indeterminacy in their performance.

8 It should be noted that we carried out an investigation of individual results in order to identify any potential outliers that might have skewed the group results. This individual subject analysis did not produce any new information to the picture provided by the group data. 
We now turn to the data from the Italian subjects in test items that were designed to test the possibilities of coreference between null and overt subjects on the one hand and other entities in the discourse on the other. In sentences of forward anaphora with a null subject in the subordinate clause such as (11), the preferred choice of referent is the subject for both groups ( $85 \%$ vs. $87 \%$ ), as shown in Figure 4. This result confirms our original hypothesis: The interpretation of null subjects is not affected by attrition since the parametric choice determining the availability of null subjects in the language remains the same. ${ }^{9}$

In contrast, Figure 5 shows that the control group differs significantly from the experimental group when the subject of the subordinate clause is an overt pronoun, as in (12). The controls strongly prefer a "new" referent for the interpretation of the subject pronoun whereas the experimental group do not show any strong preference for any of the choices (i.e., it can refer to some person not otherwise mentioned, or to the subject or complement of the matrix clause), indicating multiple ambiguity in the interpretation of the overt subject pronoun. This result also confirms our original prediction, that is, that the interpretation of overt pronouns will show attrition effects (see also fn.9 regarding individual results).

Figures 6 and 7 present results from sentences with backward anaphora such as (13) and (14). In the null pronoun case (see Fig. 6), the controls seem to allow for either the matrix subject or the complement as a possible referent whereas the experimental group strongly prefers the subject interpretation ( $51 \%$ in the controls' responses vs. $70 \%$ in the experimental group's responses): this is an unexpected result. We hypothesize that the experimental group may treat the subordinate clause as a nonfinite one (as in the English sentence The old woman greets the girl when crossing the street) in which case the matrix subject is necessarily the controller of the null subject in the subordinate clause ${ }^{10}$.

When the embedded subject is an overt pronoun, as in (14), the two groups show a similar strong preference for the matrix complement to be the referent of the pronoun ( $82 \%$ and $72 \%$ respectively - see Fig. 7). Crucially, however, the difference in the choice of the matrix subject as a possible referent is significant between the control and the experimental groups ( $8 \%$ vs. $21 \%$ respectively). This result is consistent with our original prediction that the interpretation of overt pronouns will show attrition effects: The experimental group is showing a significantly greater tendency to allow an overt pronoun to be interpreted as a continued topic.

9 Syntactic correlates of this parametric choice (in particular, wh-movement of subjects) were tested in a grammaticality judgment task; for details, consult the full report on the project (see fn. 7).

10 The reviewer points out that a similar misrepresentation of the embedded clause as a nonfinite one should also be possible in the case of forward anaphora. It is possible that this is due to differences between forward and backward anaphora which we did not explicitly consider in relation to our predictions. Although purely speculative, our suggestion is that subjects in the experimental group may notice the finiteness of the embedded clause in the case of forward anaphora due to the linear precedence of the clause. If this is the case, then we expect them to behave unlike the controls in their choice of referent for the null subject. 


\section{Conclusion}

Overall, the results reported here support our initial hypothesis concerning the nature of syntactic attrition. That is, we found no evidence of attrition in either Greek or Italian native speakers in aspects of the syntax of "subjects" that have been argued to be due to the parameterization of purely formal, or uninterpretable features. Conversely, we did find evidence of attrition in both experimental groups in aspects of the distribution and interpretation of subjects that are due to syntactic/pragmatic, or interpretable features. This study then is a contribution from the study of attrition to recent and ongoing research concerning the distinction between these two classes, which has so far not considered this type of data. More generally, with this study we have established that it is possible to devise experiments that will yield quantitative results concerning attrition in speakers who still maintain active use of their L1.

\section{References}

ANDERSON, M. (1992). Intelligence and development: A cognitive theory. Oxford: Blackwell.

BECK, M. L. (1998). L2 acquisition and Obligatory Head Movement: English-speaking learners of German and the Local Impairment Hypothesis. Studies in Second Language Acquisition, 20, $311-348$.

BELLETTI, A. (1988). The case of unaccusatives. Linguistic Inquiry, 19, 1 - 34.

BELLETTI, A. (2001). "Inversion" as focalisation. In A. Hulk \& J.-Y. Pollock (Eds.), Subject inversion in romance and the theory of universal grammar (pp.60-90). Oxford University Press.

BIRDSONG, D. (1999). Second language acquisition and the critical period hypothesis. Mahwah, NJ: Lawrence Erlbaum.

BORER, H. (1984). Parametric syntax: Case studies in Semitic and Romance languages. Dordrecht: Foris Publications.

CARDINALETTI, A. (1997). Subjects and clause structure. In L. Haegeman (Ed.), New comparative syntax. Longman Linguistics Library.

CARDINALETTI, A., \& STARKE, M. (2001). The typology of structural deficiency. A case study of the three classes of pronouns. In H. van Riemsdijk (Ed.), Clitics in the languages of Europe, Vol. 8 of Language Typology. Berlin: Mouton de Gruyter.

CHOMSKY, N. (1986). Knowledge of language: Its nature, origin and use. New York: Praeger.

CHOMSKY, N. (1995). The minimalist program. Cambridge, MA: MIT Press.

DIESING, M. (1991). Indefinites. Cambridge, MA: MIT Press.

FODOR, J. (1983). The modularity of mind. Cambridge, MA: MIT Press.

GRIMSHAW, J., \& SAMEK-LODOVICI, V. (1998). Optimal subjects and subject universals. In P. Barbosa, D. Fox, P. Hangstrom, M. McGinnis \& D. Pesetsky (Eds.), Is the best good enough? Optimality and competition in syntax (pp. 193 - 219). Cambridge, MA: MIT Press.

GUASTIBEWLITX, M. (2002). Language acquisition: The growth of grammar. Cambridge, MA: MIT Press.

GÜREL, A. (2002). First language attrition: The effects of second language. In B. Skarabela, S. Fish \& A. H. J. Do (Eds.), Proceedings of the $26^{\text {th }}$ Annual Boston University Conference on Language Development, 26(1): 255 - 265.

HÅKANSSON, G. (1995). Syntax and morphology in language attrition: A study of five bilingual expatriate Swedes. International Journal of Applied Linguistics, 5(2), 153 - 171. 
HYAMS, N. (2001). Now you hear it, now you don't: The nature of optionality in child grammars. In Proceedings of the $25^{\text {th }}$ Annual Boston University Conference on Language Development (pp. 34 - 58). Somerville, MA: Cascadilla Press.

LAMBERT, R. D., \& FREED, B. (Eds.). (1982). The loss of language skills. Rowley, MA: Newbury House.

MEISEL, J. (Ed.). (1994). Bilingual first language acquisition: French and German grammatical development. Amsterdam: John Benjamins.

MONTAlBETTI, M. (1984). After binding. Ph.D. dissertation, MIT, Cambridge. Mass.

MONTRUL, S. (2002) Divergent acquisition and attrition of Spanish Tense/Aspect distinctions in adult bilinguals. Bilingualism: Language and Cognition, 5(1).

OUHALLA, J. (1991). Functional categories and parametric variation. Routledge.

PHILIPPAKI-WARBURTON, I. (1987). The theory of empty categories and the pro-drop parameter in Modern Greek. Journal of Linguistics, 23, 289 - 318.

PINTO, M. (1997). Licensing and interpretation of inverted subjects in Italian. Ph.D. dissertation, University of Utrecht.

PLATZACK, C. (1999). Multiple Interfaces. (ms). Lund University, Dept. of Scandinavian Linguistics.

RIZZI, L. (1982). Issues in Italian syntax. Dordrecht: Foris.

RIZZI, L. (1986). Null objects in Italian and the theory of pro. Linguistic Inquiry, 17, $501-555$.

ROBERTSON, D., \& SORACE, A. (1999). Losing the V2 constraint. In E. Klein \& G. Martohardjono (Eds.), The development of second language grammars: A generative approach. Amsterdam: John Benjamins.

ROUSSOU, A., \& TSIMPLI, I. (to appear). On VSO again! To appear in Journal of Linguistics.

SELIGER, H. W. (1991). Language Attrition, reduced redundancy and creativity. In H. W. Seliger \& R. M. Vago (Eds.), First language attrition (pp. 227 - 240). Cambridge University Press.

SILVA-CORVALAN, C. (1991). Spanish language attrition in a contact situation with English. In H. Seliger \& R. M. Vago (Eds.), First language attrition. Cambridge University Press.

SMITH, N., \& TSIMPLI, I. (1995). The mind of a Savant: Language learning and modularity. Blackwell.

SORACE, A. (1993). Incomplete versus divergent representations of unaccusativity in non-native grammars of Italian. Second Language Research, 9, 22 - 47.

SORACE, A. (2000). Differential effects of attrition in the L1 syntax of L2 near-native speakers. In BUCLD Proceedings 24, Somerville, MA: Cascadilla Press.

SORACE, A. (2003). Near-nativeness. In M. Long \& C. Doughty (Eds.), Handbook of second language acquisition. Oxford: Blackwell.

TSIMPLI, I. (1990). The clause structure and word-order of Modern Greek. University College London Working Papers in Linguistics, 2, 226 - 258.

TSIMPLI, I. (1997). Resumptive strategies and second language acquisition: A minimalist account. In BUCLD Proceedings 21 (pp.639-655). Somerville, MA: Cascadilla Press.

TSIMPLI, I. (2001). LF-Interpretability and language development: A study of verbal and nominal features in Greek normally developing and SLI children. Brain and Language, $77,432-448$.

WELTENS, B., de BOT, K., \& van ELS, T. (1986). Language attrition in progress. Dordrecht: Foris.

WEXLER, K. (1996). The development of inflection in a biologically-based theory of language acquisition. In M. L. Rice (Ed.), Toward a genetics of language (pp. 113 - 144). Mahwah, NJ: Lawrence Erlbaum,

WHITE, L. (2000). Second language acquisition: From initial to final state. In J. Archibald (Ed.), Second language acquisition and linguistic Theory. Oxford: Blackwell.

WHITE, L., \& GENESEE, F. (1996). How native is near-native? The issue of ultimate attainment in adult second language acquisition. Second Language Research, 12, 233 - 265. 


\section{Appendix}

\section{Item A: Headlines Task}

\section{Instructions (in English)}

Imagine you are on the phone talking to an Italian friend. In front of you, there is a photograph that appeared on a newspaper with some words describing it. Your task is to report to your friend the piece of news illustrated by the photograph using the words provided in the form they are presented. You will start your sentence with the words: "Hai sentito che ...?"

The sentence has to be uttered aloud and it will be recorded. When you are done with a sentence, press the green button in front of you, at the front of the keyboard, to go on to the following one.

Before the beginning of the experiment you will see two practice items, after those the test will start.

Have you heard that...

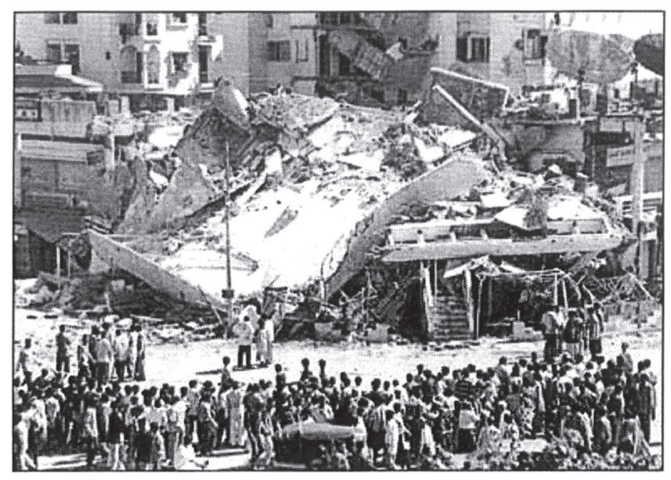

Have you heard that ...

because of an explosion

a building

collapsed

\section{Instructions for the PVT Task (in English)}

During this part of the experiment you will see isolated sentences on the screen. Once you have read a sentence, if you press the green button at the front of the keyboard, three pictures will appear on the screen, below the sentence. Each picture will be identified by a number below it. Your task will consist in indicating which of the pictures represent exactly the content of the sentence by typing in the number corresponding to them. In 
some cases only one picture matches the meaning of the sentence, in other cases there can be more than one.

If you think that more than one picture match exactly the meaning of the sentence, type in the numbers corresponding to the pictures one after the other. When you have finished with one sentence, press again the green button to go on to the next. Try not to spend too much time on each sentence: what we are interested in is your spontaneous impression.

Before the beginning of the experiment you will see two practice items, after those, the real experiment will begin.

\section{Item B: PVT Task, Item type 1}

L'anziana signora saluta la ragazza, quando lei attraversa la strada. (The old lady waves at the girl, when (SHE) crosses the street.)
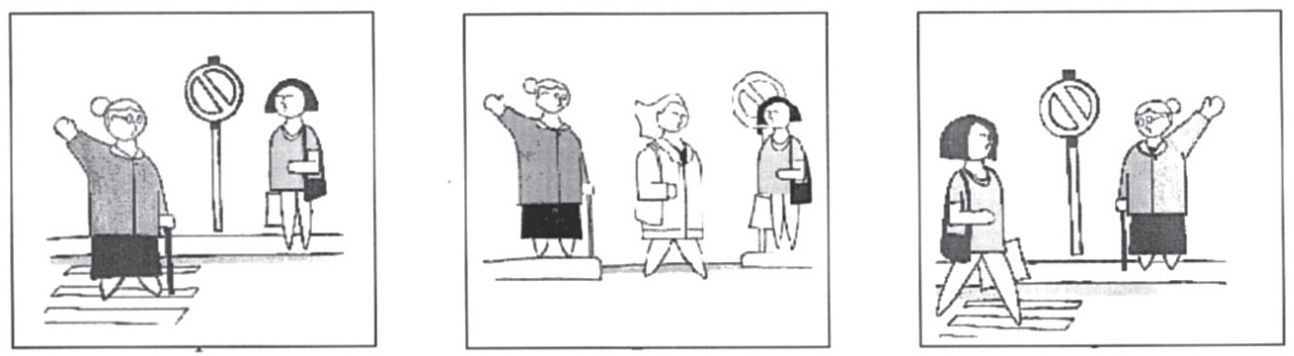

\section{Item C: PVT Task, Item Type 2}

La vicina dell'ultimo piano ha due gemelli. La notte scorsa piangeva un bambino. (My neighbour on the top floor has two babies. Last night cried a baby.)
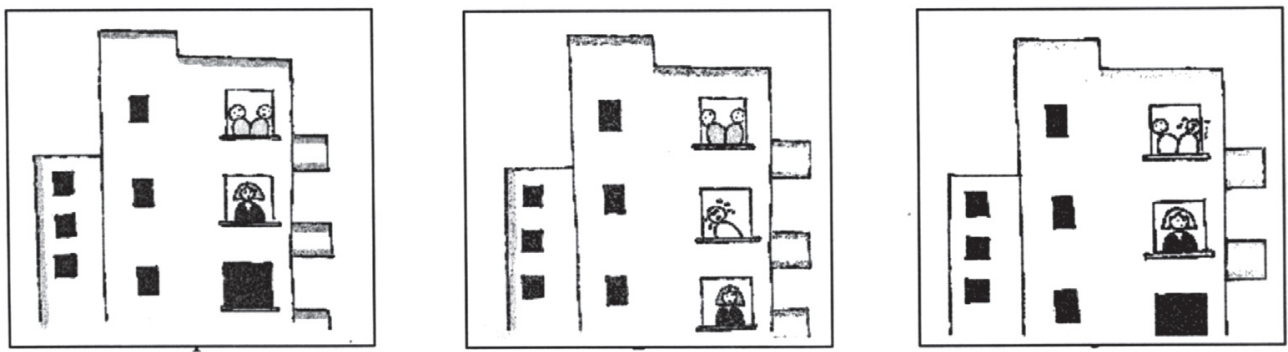